\title{
CRESCIMENTO DIFERENCIAL DE BIÓTIPOS DE CONYZA SPP. RESISTENTE E SUSCETÍVEL AO HERBICIDA GLIFOSATO ${ }^{\left({ }^{1}\right)}$
}

\author{
MURILO SALA MOREIRA (2); MARCEL SEREGUIN CABRAL DE MELO (3); SAUL JORGE PINTO \\ DE CARVALHO $\left(\left(^{*}\right)\right.$; PEDRO JACOB CHRISTOFFOLETI $\left({ }^{5}\right)$
}

\begin{abstract}
RESUMO
Este trabalho foi realizado com o objetivo de comparar, em condição controlada e não-competitiva, o crescimento de biótipos de Conyza canadensis e C. bonariensis resistente e suscetível ao herbicida glifosato, a fim de quantificar os efeitos da pressão de seleção para resistência nos biótipos. Dois experimentos foram desenvolvidos com tratamentos organizados em esquema fatorial $9 \times 2$, com nove avaliações periódicas de crescimento e dois biótipos de cada espécie. As variáveis avaliadas por planta foram: área foliar; massa seca da parte aérea, das raízes e total, obtendo-se, a partir desta última, a taxa de crescimento absoluto. O biótipo de C. canadensis resistente ao glifosato possui crescimento mais lento, menor acúmulo de área foliar e de massa seca que o biótipo suscetível. Menores áreas foliar e massa seca também foram registradas para o biótipo de $C$. bonariensis resistente ao glifosato quando comparado ao suscetível, porém com diferenças mais sutis que aquelas constatadas para $C$. canadensis. $\mathrm{O}$ crescimento absoluto do biótipo suscetível foi superior ao do resistente em ambas as espécies. A pressão de seleção para resistência ao glifosato teve impactos negativos na habilidade de crescimento dos biótipos.
\end{abstract}

Palavras-chave: buva, resistência, desenvolvimento, ecologia, populações.

\section{ABSTRACT \\ DIFFERENTIAL GROWTH OF GLYPHOSATE-RESISTANT AND SUSCEPTIBLE BIOTYPES OF CONYZA SPP.}

This work was carried out with the objective of comparing, under controlled and non-competitive condition, the growth of glyphosate-resistant and susceptible biotypes of Conyza canadensis and C. bonariensis; to quantify the effects of resistance selection pressure on the biotypes. Two trials were developed with treatments organized according to a factorial scheme $9 \times 2$, where nine were periodical growth evaluations and two were biotypes of each species. The variables evaluated per plant were: leaf area and dry mass (shoot, root and total); to determine absolute growth rate from the total dry mass. The glyphosate-resistant biotype of $C$. canadensis exhibits slower growth and smaller accumulation of leaf area and dry mass than the susceptible biotype. Lower leaf area and dry mass were also registered for the glyphosate-resistant biotype of $C$. bonariensis when compared to the susceptible one, however with more subtle differences than those identified for $C$. canadensis. Absolute growth rate of susceptible biotype was superior to that of resistant ones for both species. The pressure of selection to glyphosate resistance had negative impacts on the biotype growth.

Key words: horseweed, resistance, development, ecology, populations.

(1) Parte da dissertação do primeiro autor apresentada à ESALQ para a obtenção do título de mestre em agronomia. Recebido para publicação em 16 de janeiro de 2009 e aceito em 26 de janeiro de 2010.

(2) Engenheiro Agrônomo, M.Sc. E-mail: murilosala9@hotmail.com.

(3) Mestrando em Fitotecnia - ESALQ/USP. E-mail: melomsc@yahoo.com.br.

(4) Instituto Federal de Educação, Ciência e Tecnologia do Sul de Minas Gerais. Caixa Postal 1004, 37750-971 Machado (MG). E-mail: sjpcarvalho@yahoo.com.br $\left(^{*}\right)$ Autor correspondente.

(5) Departamento de Produção Vegetal, ESALQ/USP. E-mail: pjchrist@esalq.usp.br. 


\section{INTRODUÇÃO}

No Brasil, espécies de buva (Conyza spp.) são plantas comumente constatadas infestando pomares de citros. Estas espécies também são identificadas em terrenos abandonados, áreas em pousio, sob semeadura direta, cultivo mínimo ou outros sistemas de produção fundamentados no manejo conservacionista do solo (BHOWMiк е Векесн, 1993; ТнEвAUd e Аввотт, 1995).

$\mathrm{O}$ gênero Conyza contém aproximadamente 50 espécies, sendo C. canadensis (L.) Cronquist e $C$. bonariensis (L.) Cronquist aquelas que mais se destacam como infestantes de cultivos (Kissmann e Groth, 1999). São espécies altamente prolíficas, podendo produzir cerca de 200.000 sementes viáveis por planta (BHOWMIK e BEKECH, 1993); desenvolvem-se bem em solos ácidos e arenosos, sendo também tolerantes ao estresse hídrico (HANF, 1983).

A aplicação de herbicidas tem sido a medida de controle adotada com mais frequência visando ao manejo de plantas daninhas em áreas agrícolas, devido à eficácia, facilidade de utilização e viabilidade de custos (ABDin et al., 2000; JAKELAITIS et al., 2005). Nos pomares de citros do Estado de São Paulo, aplicações do herbicida glifosato são realizadas rotineiramente para manejo de plantas daninhas e, por consequência destas pulverizações constantes, foram selecionados indivíduos resistentes ao produto nas populações de buva (MoreIRA et al., 2007).

A habilidade de autopolinização e a produção de grande número de sementes facilmente disseminadas são fatores que podem contribuir para a sobrevivência, o estabelecimento e a manutenção de densas infestações dos biótipos resistentes de buva (THEBAUD et al., 1996; MOREIRA et al., 2007).

Segundo López-Ovejero et al. (2008), alguns dos princípios básicos para prevenção e manejo da resistência são: redução na pressão de seleção por meio do planejamento criterioso da aplicação de herbicidas com diferentes mecanismos de ação; adoção de técnicas culturais com efeito na dinâmica populacional das sementes de plantas daninhas no banco de sementes do solo, sendo retardado o aumento da frequência de sementes resistentes; conhecimento da adaptabilidade ecológica do biótipo resistente em relação ao suscetível para compreensão de seu comportamento na área afetada.

Diferenças na adaptabilidade ecológica entre biótipos resistentes e suscetíveis são usualmente aferidas a partir da comparação de diferentes variáveis, tais como: vigor da planta, produtividade ou competitividade. Estas podem ser medidas em experimentos desenvolvidos com o objetivo de se avaliarem a produção e a dormência de sementes, época de florescimento, fitomassa produzida e outros fatores com efeito na sobrevivência e fecundação das espécies (WARWICK e BLACK, 1994; RADOSEVICH et al., 1997).

Assim, este trabalho foi desenvolvido com o objetivo de se comparar, em condição controlada e não-competitiva, o crescimento de biótipos de Conyza canadensis e $C$. bonariensis resistente e suscetível ao herbicida glifosato, a fim de quantificar os efeitos da pressão de seleção para resistência nos referidos biótipos.

\section{MATERIAL E MÉTODOS}

Dois experimentos foram desenvolvidos em casa de vegetação, em Piracicaba ( $22^{\circ} 42^{\prime} 30^{\prime \prime}$ S, $47^{\circ} 38^{\prime} 00^{\prime \prime}$ W e $546 \mathrm{~m}$ de altitude), janeiro e abril de 2007, analisando-se, separadamente, o crescimento de biótipos das espécies daninhas $C$. canadensis e $C$. bonariensis. Os biótipos utilizados no experimento foram os mesmos avaliados por MoReIRA et al. (2007), que comprovaram a ocorrência de resistência ao glifosato nas duas espécies. Para diferenciar os materiais, foram concedidas as seguintes denominações: $C$. canadensis resistente (CCR1), Conyza canadensis suscetível (CCS), C. bonariensis resistente (CBR1) e C. bonariensis suscetível (CBS).

Os propágulos dos biótipos CCR1 e CBR1 foram coletados em pomares de citros da fazenda Cambuhy, município de Matão (SP), com histórico de mais de dez anos de aplicações de glifosato; os propágulos dos biótipos CCS e CBS foram coletados em Piracicaba (SP), em áreas sem histórico da aplicação do produto. As sementes foram acondicionadas em sacos de papel em local seco, à temperatura ambiente, até a instalação dos experimentos.

Em 15/1/2007, sementes dos quatro biótipos de Conyza spp. foram distribuídas separadamente em caixas plásticas com capacidade para $2 \mathrm{~L}$, preenchidas com mistura de substrato comercial (turfa + vermiculita + casca de Pinus) e terra arenosa (horizonte superficial de um Neossolo Quartzarênico), em proporção de 1:1. As caixas foram mantidas em câmara de germinação com condições alternadas de 12 horas de luz $/ 30^{\circ} \mathrm{C}$ e 12 horas de escuro $/ 20^{\circ} \mathrm{C}$, por cinco dias.

Quando se constatou estádio de folhas cotiledonares plenamente expandidas, ou seja, estádio 10 (Hess et al., 1997), as plântulas foram transplantadas para as unidades experimentais, onde permaneceram até o fim do experimento. Cada parcela constou de um vaso plástico com capacidade de 4,0 L, preenchido com vermiculita e irrigado diariamente com $200 \mathrm{~mL}$ de solução nutritiva contendo $\left(\mathrm{mg} \mathrm{L}^{-1}\right)$ : 110 de N; 60 de 
$\mathrm{P}_{2} \mathrm{O}_{5} ; 160$ de $\mathrm{K}_{2} \mathrm{O} ; 17$ de $\mathrm{S} ; 95$ de Ca; 10 de $\mathrm{Mg} ; 1,5$ de Fe; 0,5 de Zn; 0,2 de Mn; 0,2 de B; 0,5 de Cu e 0,06 de Mo.

Foram transplantadas quatro plantas por vaso, contudo, no momento da primeira avaliação, efetuou-se o desbaste das três plantas menos desenvolvidas. Em ambos os experimentos, o delineamento experimental adotado foi o de blocos ao acaso com três repetições. Os tratamentos foram organizados segundo esquema fatorial $9 \times 2$, com nove avaliações periódicas de crescimento $(25,35,47,57,67,78,91,97$ e 120 dias após emergência - DAE) e dois biótipos de cada espécie, totalizando 54 parcelas por experimento.

Para cada avaliação, três plantas (repetições) foram aleatoriamente amostradas pelo método destrutivo e lavadas em água corrente para a retirada da vermiculita remanescente nas raízes. A área foliar $\left(\mathrm{cm}^{2}\right.$ planta $\left.{ }^{-1}\right)$ das plantas foi obtida com auxílio do medidor de área modelo LICOR LI-3100. O material amostrado foi seco em estufa de circulação forçada de ar a $70^{\circ} \mathrm{C}$ por 72 horas. Após secagem, avaliou-se a massa seca (g planta ${ }^{-1}$ ) da parte aérea, das raízes e total. Para evitar a dispersão de grande quantidade de sementes de buva resistentes ao herbicida glifosato, os experimentos foram desenvolvidos somente até a emissão dos capítulos, o que acorreu próximo aos 120 dias.

Em cada avaliação, com as médias da variável massa seca total, calculou-se a taxa de crescimento absoluto $\left(G, \mathrm{~g} \mathrm{dia}^{-1}\right)$ a partir da fórmula:

$$
G=\frac{M_{t_{2}}-M_{t_{1}}}{t_{2}-t_{1}},
$$

em que: $M_{\mathrm{t} 2}$ e $M_{\mathrm{t} 1}$ são as massas secas totais de duas amostras sucessivas; e $t_{2}$ e $t_{1}$ são os dias decorridos entre as avaliações (CAlBo et al., 1989; Hunt, 1990; CARvalHO et al., 2008).

Separadamente para cada experimento, os dados foram submetidos à aplicação do teste $\mathrm{F}$ na análise da variância. Quando constatados efeitos significativos para as variáveis, os biótipos foram comparados pelo teste de Tukey, a 5\% de significância, enquanto os períodos de avaliação foram ajustados por meio de regressões não-lineares, com o objetivo de modelar os dados sob a forma de equações (CARvALHo et al., 2008).

As variáveis massa seca e área foliar foram ajustadas ao modelo de regressão não-linear do tipo logístico, adaptado de STREIBIG (1988):

$$
y=\frac{a}{\left[1+\left(\frac{x}{b}\right)^{c}\right]}
$$

em que: $y=$ variável resposta; $x=$ dias após emergência; e $a, b$ e $c=$ parâmetros da curva, de modo que $a$ é a diferença entre o ponto máximo e mínimo da curva, $b$ é o tempo no qual se obtém $50 \%$ de resposta da variável e $c$ é a declividade da curva.

O crescimento absoluto foi ajustado ao modelo de regressão não-linear do tipo logístico, também utilizado por CARVALHO et al. (2008):

$$
y=4 a \cdot \frac{\exp \left[-\left(\frac{x-b}{c}\right)\right]}{\left[1+\exp \left[-\left(\frac{x-b}{c}\right)\right]\right]^{2}},
$$

em que: $y$ é a variável de interesse, $x$ é o número de dias acumulados; $a, b$, e $c$ são parâmetros estimados da equação ( $a$ é a amplitude existente entre o ponto máximo e o ponto mínimo, $b$ é o número de dias acumulados correspondente ao ponto máximo da curva e $c$ é a inclinação da curva).

\section{RESULTADOS E DISCUSSÃO}

Os parâmetros das curvas de crescimento dos biótipos CCR1 e CCS estão apresentados na tabela 1 .

\begin{tabular}{|c|c|c|c|c|c|c|}
\hline \multirow{2}{*}{ Variável } & \multirow{2}{*}{ Biótipo } & \multicolumn{3}{|c|}{ Parâmetros } & \multirow{2}{*}{$\mathrm{F}$} & \multirow{2}{*}{$\mathrm{R}^{2}$} \\
\hline & & a & $\mathrm{b}$ & $\mathrm{c}$ & & \\
\hline \multirow{2}{*}{ Área foliar $\left(^{1}\right)$} & CCR1 & 1590,835 & 88,536 & $-7,403$ & $135,001 *$ & 0,975 \\
\hline & $\mathrm{CCS}$ & 2068,563 & 81,397 & $-13,085$ & $62,071 *$ & 0,947 \\
\hline \multirow{2}{*}{ Massa seca da parte aérea $\left({ }^{1}\right)$} & CCR1 & 6,521 & 84,053 & $-14,577$ & $90,183 *$ & 0,963 \\
\hline & CCS & 14,297 & 85,894 & $-13,303$ & $246,079 *$ & 0,986 \\
\hline \multirow{2}{*}{ Massa seca das raízes $\left({ }^{1}\right)$} & CCR1 & 3,673 & 90,868 & $-29,731$ & $51,425^{*}$ & 0,936 \\
\hline & $\mathrm{CCS}$ & 7,370 & 80,727 & $-14,854$ & $160,392 *$ & 0,979 \\
\hline \multirow{2}{*}{ Massa seca total $\left({ }^{1}\right)$} & CCR1 & 10,288 & 84,879 & $-14,034$ & $67,797 *$ & 0,951 \\
\hline & CCS & 21,549 & 83,809 & $-13,296$ & $304,578 *$ & 0,988 \\
\hline
\end{tabular}

Tabela 1. Parâmetros do modelo logístico, teste $\mathrm{F}$ e coeficiente de determinação $\left(\mathrm{R}^{2}\right)$ para o ajuste da área foliar e massa seca (parte aérea, raízes e total) dos biótipos de Conyza canadensis resistente (CCR1) e suscetível (CCS) ao glifosato. Piracicaba (SP), 2007

(1) Modelo: $\mathrm{y}=\mathrm{a} /(1+(\mathrm{x} / \mathrm{b}) \mathrm{c}) ;{ }^{*}$ Teste F significativo a $1 \%$. 
Para as variáveis área foliar e massa seca da parte aérea constatou-se maior amplitude de resposta (a) para o biótipo suscetível, porém com valores similares de $b$, o que pode ser confirmado pelas figuras $1 \mathrm{~A}$ e $1 \mathrm{~B}$. O tempo necessário para acúmulo de $50 \%$ da área foliar e massa seca da parte aérea foi similar entre os biótipos, contudo a magnitude verificada no biótipo CCS foi superior à do biótipo CCR1.

Para a massa seca das raízes (Figura 1C), além do maior crescimento do biótipo CCS, neste também foi rápido o estabelecimento no ambiente (10 dias), resultando em menor valor de $b$ (Tabela 1). Com esta característica, podem ser proporcionadas vantagens ao biótipo CCS, visto que plantas com maior desenvolvimento radicular são favorecidas quanto à absorção de água e nutrientes (HoRAK e LOUGHIN, 2000; CARVAlHo et al., 2008). O acúmulo de massa seca total foi semelhante ao detectado para a massa da parte aérea, com maior valor de $a$ para o CCS e sem diferenças no parâmetro $b$ (Figura 1D; Tabela 1).

Resultados similares foram obtidos por VARGAS et al. (2005) em biótipos de Lolium multiflorum resistentes e suscetíveis ao herbicida glifosato no Rio Grande do Sul. Constataram menor capacidade de acúmulo de massa seca e produção de sementes no biótipo resistente. No entanto, em outro trabalho, em que foi estudada a espécie
Eleusine indica, foi constatada adaptabilidade ecológica semelhante entre os biótipos resistente e suscetível ao glifosato (Ismail et al., 2002).

Nos casos da resistência de plantas daninhas aos herbicidas inibidores da ACCase e ALS, em geral, não têm sido verificadas diferenças entre o crescimento dos diferentes biótipos (Christoffoleti et al., 1997; Christoffoleti, 2001; López-Ovejero et al., 2007). O mecanismo de resistência de plantas daninhas aos inibidores da ACCase e ALS está frequentemente correlacionado com a alteração na enzima alvo, cuja mutação é insensível aos herbicidas, sem desvantagem ao crescimento na ausência de pressão de seleção (Sathasivan et al., 1990; Devine, 1997). No presente trabalho, de acordo com os resultados referentes ao crescimento da espécie, sugere-se que, devido ao mecanismo de resistência ao glifosato presente em C. canadensis, sejam promovidas alterações no desenvolvimento das plantase, portanto, não devehaver relação somente com a insensibilidade enzimática.

Diversas pesquisas foram realizadas nos últimos anos com o objetivo de ser elucidado o mecanismo de resistência de plantas daninhas ao glifosato; no entanto, o assunto ainda não está completamente esclarecido. POWles e PReston (2006) comentam sobre dois
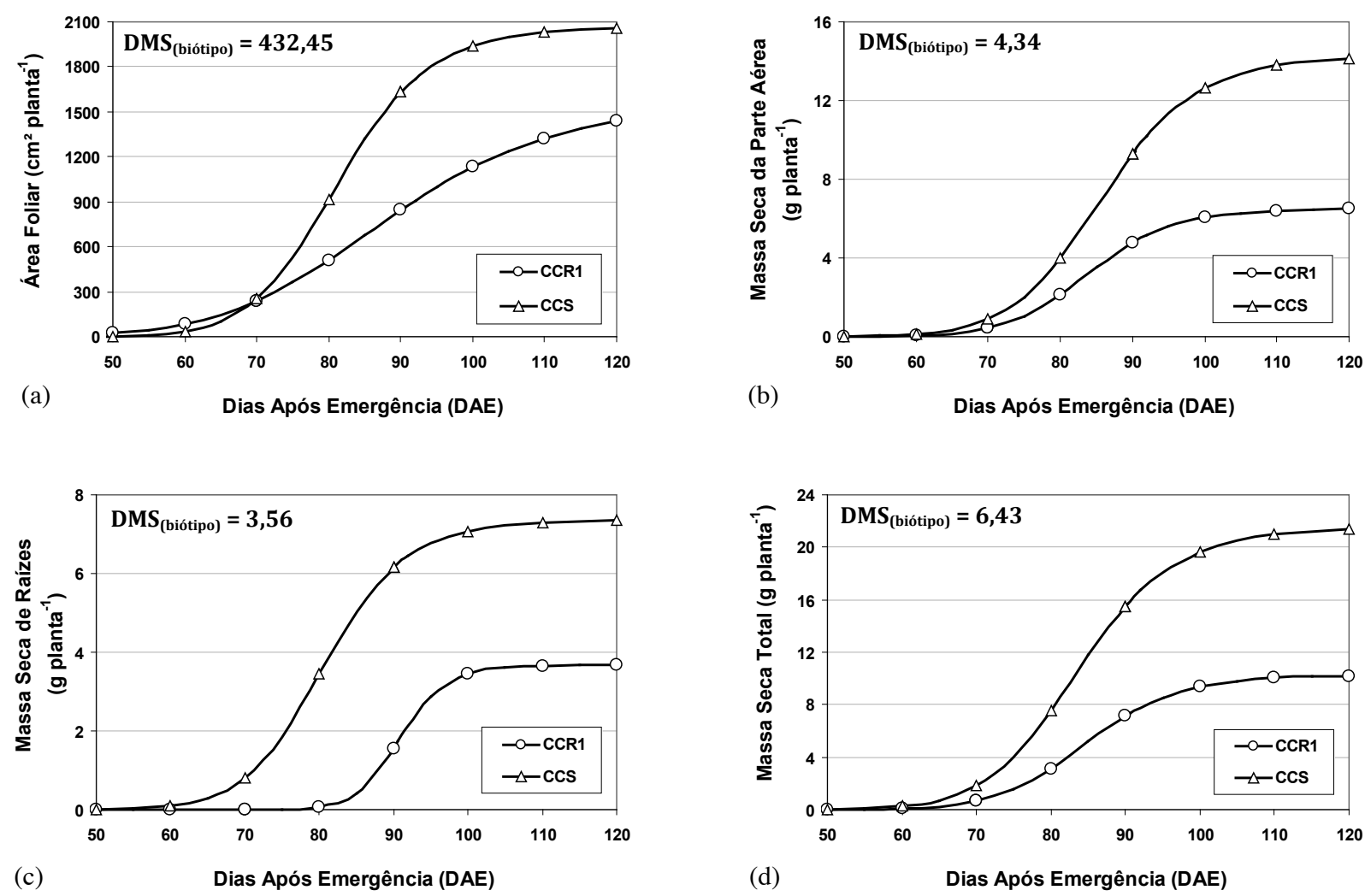

Figura 1. Acúmulo de área foliar (a) e das massas secas da parte aérea (b), de raízes (c) e total (d) de biótipos de Conyza canadensis resistente (CCR1) e suscetível (CCS) ao herbicida glifosato. Piracicaba (SP), 2007. Símbolos representam o valor ajustado de cada variável. 
mecanismos de resistência que já foram parcialmente elucidados: a reduzida translocação do glifosato para as zonas meristemáticas da planta e a alteração no sítio de ação do herbicida. Em outros trabalhos desenvolvidos com populações resistentes de C. canadensis, foi determinada menor taxa de translocação do glifosato das zonas tratadas para outras partes da planta, o que não é constatado nas plantas suscetíveis (FENG et al., 2004; Koger e RedDy, 2005). Não são conhecidas, porém, as características bioquímicas e moleculares relacionadas com essa translocação diferencial do glifosato.

As diferenças de crescimento dos biótipos CBR1 e CBS (Tabela 2) não foram tão evidentes quanto aquelas obtidas para C. canadensis. O parâmetro $b$ esteve próximo entre os biótipos para todas as variáveis, com maior tendência à diferença para a massa seca das raízes. Por outro lado, segundo os valores de $a$ (amplitude),

Tabela 2. Parâmetros do modelo logístico, teste $\mathrm{F}$ e coeficiente de determinação $\left(\mathrm{R}^{2}\right)$ para o ajuste da área foliar e massa seca (parte aérea, raízes e total) dos biótipos de Conyza bonariensis resistente (CBR1) e suscetível (CBS) ao glifosato. Piracicaba (SP), 2007

\begin{tabular}{|c|c|c|c|c|c|c|}
\hline \multirow{2}{*}{ Variável } & \multirow{2}{*}{ Biótipo } & \multicolumn{3}{|c|}{ Parâmetros } & \multirow{2}{*}{$\mathrm{F}$} & \multirow{2}{*}{$\mathrm{R}^{2}$} \\
\hline & & $\mathrm{a}$ & $\mathrm{b}$ & $\mathrm{c}$ & & \\
\hline \multirow{2}{*}{ Área foliar ( $\left.{ }^{1}\right)$} & CBR1 & 546,690 & 81,945 & $-6,291$ & $75,132 *$ & 0,955 \\
\hline & CBS & 577,009 & 79,119 & $-9,567$ & $46,463 *$ & 0,929 \\
\hline \multirow{2}{*}{ Massa seca da parte aérea $\left({ }^{1}\right)$} & CBR1 & 2,654 & 83,030 & $-11,612$ & $109,636 *$ & 0,969 \\
\hline & CBS & 3,308 & 82,735 & $-11,250$ & $118,349^{*}$ & 0,971 \\
\hline \multirow{2}{*}{ Massa seca das raízes $\left({ }^{1}\right)$} & CBR1 & 1,619 & 84,477 & $-11,064$ & $1978,252 *$ & 0,998 \\
\hline & CBS & 2,581 & 89,433 & $-8,032$ & $640,706^{*}$ & 0,995 \\
\hline \multirow{2}{*}{ Massa seca total $\left({ }^{1}\right)$} & CBR1 & 4,266 & 83,525 & $-11,484$ & $244,425^{*}$ & 0,986 \\
\hline & CBS & 5,780 & 84,715 & $-9,640$ & $213,462 *$ & 0,984 \\
\hline
\end{tabular}

( $\left.{ }^{1}\right)$ Modelo: $\mathrm{y}=\mathrm{a} /(1+(\mathrm{x} / \mathrm{b}) \mathrm{c}) ;{ }^{*}$ Teste F significativo a $1 \%$.
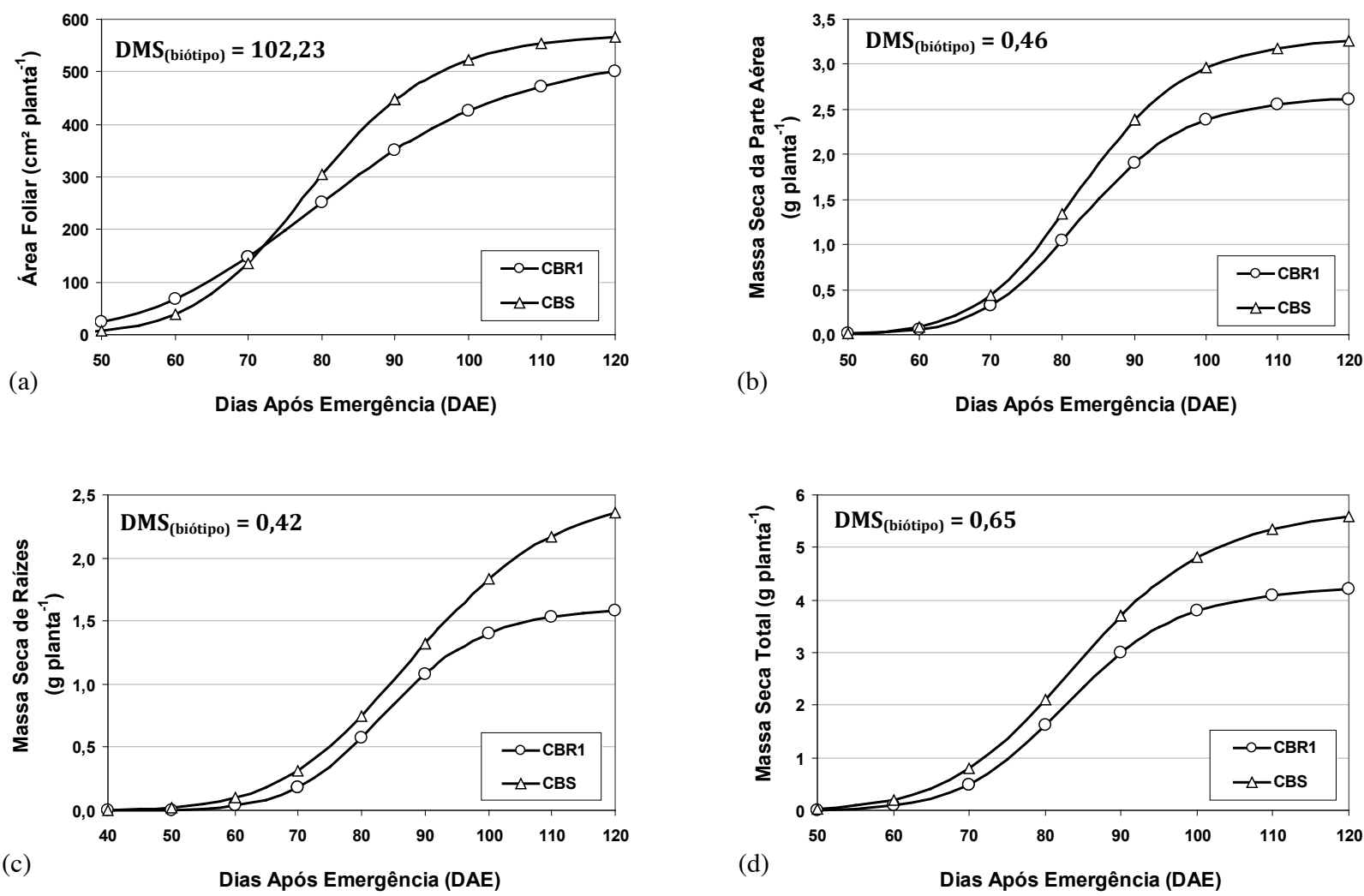

Figura 2. Acúmulo de área foliar (a) e das massas secas da parte aérea (b), de raízes (c) e total (d) de biótipos de Conyza bonariensis resistente (CBR1) e suscetível (CBS) ao herbicida glifosato. Piracicaba (SP), 2007. Símbolos representam o valor ajustado de cada variável. 
há possíveis diferenças de crescimento dos biótipos (Tabela 2), confirmadas na figura 2, sobretudo para massa seca das raízes e total, aos 120 DAE.

A taxa de crescimento absoluto $(G)$ é uma estimativa da velocidade média de crescimento das plantas ao longo do período de observação (Evans, 1972; Aguilera et al., 2004). Para Vidal e TrezZI (2000), espécies com elevada $G$ podem ter vantagem competitiva em virtude da ocupação rápida do espaço e do encerramento mais rápido do ciclo. Para ambas as espécies, a taxa de crescimento absoluto foi estável no início do ciclo, com rápido aumento a partir dos $60 \mathrm{DAE}$ e máximo crescimento entre os 90 e 100 DAE (Tabela 3; Figura 3). Comparando-se as duas espécies, maiores valores de $G$ foram constatados para $C$. canadensis e, para ambas as espécies, os biótipos suscetíveis foram aqueles com as taxas mais elevadas em período mais precoce (Figura 3).

As diferenças registradas para massa seca e crescimento absoluto são evidências de crescimento diferencial dos biótipos, do que pode resultar diferença competitiva. $\mathrm{O}$ biótipo suscetível possui maior habilidade de crescimento que o resistente, de modo que a dominância numérica do biótipo resistente em relação ao suscetível, verificada em condição de campo, é decorrente apenas da pressão de seleção causada pelo herbicida.

Nas plantas, a rota de translocação de glifosato é predominantemente a do transporte de fotoassimilados, no sentido fonte-dreno, com acúmulo nas raízes, pontos de crescimento e regiões meristemáticas (ARNAUD et al., 1994; Monquero et al., 2004). Porém, nos biótipos de $C$. bonariensis resistentes ao glifosato, FERREIRA et al. (2008) verificaram translocação diferencial do produto em relação ao biótipo suscetível, no qual houve mais exportação do glifosato das folhas tratadas para as demais estruturas das plantas.

Desse modo, a translocação diferencial do glifosato nos biótipos resistentes tem sido considerada como o principal mecanismo de resistência das plantas, o que sugere que o menor crescimento destes biótipos seja consequência de possível diferença na distribuição dos fotoassimilados. Segundo Pedersen et al. (2007), a translocação diferencial em plantas resistentes pode significar algum prejuízo na sua adaptabilidade ecológica.

\section{CONCLUSÕES}

1. O biótipo de Conyza canadensis resistente ao herbicida glifosato possui crescimento mais lento e

Tabela 3. Parâmetros do modelo logístico, teste F e coeficiente de determinação $\left(R^{2}\right)$ para o ajuste do crescimento absoluto dos biótipos de Conyza canadensis e C. bonariensis resistentes (CCR1 e CBR1) e suscetíveis (CCS e CBS) ao glifosato. Piracicaba (SP), 2007

\begin{tabular}{|c|c|c|c|c|c|c|}
\hline \multirow{2}{*}{ Variável } & \multirow{2}{*}{ Biótipo } & \multicolumn{3}{|c|}{ Parâmetros } & \multirow{2}{*}{$\mathrm{F}$} & \multirow{2}{*}{$\mathrm{R}^{2}$} \\
\hline & & $\mathrm{a}$ & $\mathrm{b}$ & $\mathrm{c}$ & & \\
\hline \multirow{4}{*}{ Crescimento absoluto ${ }^{(1)}$} & CCR1 & 0,756 & 96,989 & 2,908 & $62,268^{*}$ & 0,947 \\
\hline & $\mathrm{CCS}$ & 0,809 & 93,436 & 6,737 & $87,877 *$ & 0,962 \\
\hline & CBR1 & 0,156 & 97,909 & 7,320 & $71,297 *$ & 0,953 \\
\hline & CBS & 0,179 & 96,234 & 8,847 & $19,513^{*}$ & 0,848 \\
\hline
\end{tabular}

(1) Modelo: $y=4 a .\left\{\exp [-(x-b /) c] /[1+\exp [-(x-b / c)]]^{2}\right\} ;{ }^{*}$ Teste F significativo a $1 \%$.
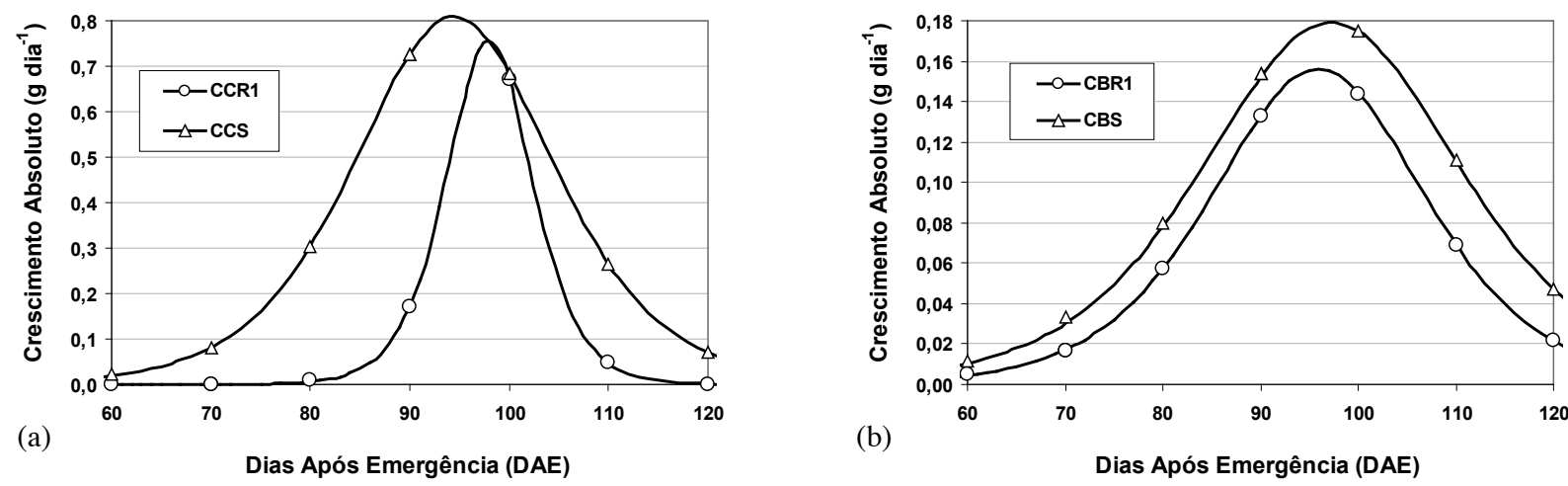

Figura 3. Crescimento absoluto de biótipos de Conyza canadensis (a) e C. bonariensis (b) resistente e suscetível ao herbicida glifosato. CCR1 - C. canadensis resistente; CCS - C. canadensis suscetível; CBR1 - C. bonariensis resistente; CBS - C. bonariensis suscetível. Piracicaba (SP), 2007. Símbolos representam o valor ajustado de cada variável. 
menores acúmulos de área foliar e de massa seca que o biótipo suscetível.

2. O biótipo de C. bonariensis resistente ao herbicida glifosato também acumula menor área foliar e massa seca quando comparado ao suscetível, porém com diferenças mais sutis que aquelas constatadas para C. canadensis.

3. O crescimento absoluto do biótipo suscetível é superior ao do resistente para ambas as espécies.

4. A pressão de seleção para resistência ao glifosato tem impactos negativos na habilidade de crescimento dos biótipos de Conyza spp.

\section{AGRADECIMENTOS}

Os autores agradecem à Coordenação de Aperfeiçoamento de Pessoal de Nível Superior (CAPES) pela bolsa de mestrado concedida ao primeiro autor.

\section{REFERÊNCIAS}

ABDIN, O.A.;ZHOU, X.M.; CLOUTIER, D.; COULMAN, D.C.; FARIS, M.A.; SMITH, D.L. Cover crops and interrow tillage for weed control in short season maize (Zea mays). European Journal of Agronomy, v.12, p.93-102, 2000.

AGUILERA, D.B.; FERREIRA, F.A.; CECON, P.R. Crescimento de Siegesbeckia orientallis sob diferentes condições de iluminação. Planta Daninha, v.22, p.43-51, 2004.

ARNAUD, L.; NURIT, F.; RAVANEL, P.; TISSUT, P. Distribution of glyphosate and its target enzyme inside wheat plants. Plant Physiology, v.40, p.217-223, 1994.

BHOWMIK, P.C.; BEKECH, M.M. Horseweed (Conyza canadensis) seed production, emergence and distribution in notillage and conventional-tillage corn (Zea mays). Agronomy, v.1, p.67-71, 1993.

CALBO, A.G.; SILVA, W.L.C.; TORRES, A.C. Comparação de modelos e estratégias para análise de crescimento. Revista Brasileira de Fisiologia Vegetal, v.1, p.1-7, 1989.

CARVALHO, S.J.P.; LÓPEZ-OVEJERO, R.F.; CHRISTOFFOLETI, P.J. Crescimento e desenvolvimento de cinco espécies de plantas daninhas do gênero Amaranthus. Bragantia, v.67, p.317-326, 2008.

CHRISTOFFOLETI, P.J.; WESTRA, P.; MORRE III, F. Growth analysis of sulfonylurea-resistant and susceptible kochia (Kochia scoparia). Weed Science, v.45, p.691-695, 1997.

CHRISTOFFOLETI, P.J. Análise comparativa do crescimento de biótipos de picão-preto (Bidens pilosa) resistente e suscetível aos herbicidas inibidores da ALS. Planta Daninha, v.19, p.7583, 2001.
DEVINE, M.D. Mechanisms of resistance to acetyl-coenzime A carboxylase inhibitors: a review. Pesticide Science, v.51, p.259-264, 1997.

EVANS, G.C. The quantitative analysis of plant growth. London: Blackwell Scientific, 1972. 734p.

FENG, P.C.C.; TRAN, M.; CHIU, T.; SAMMONS, R.D.; HECK, G.R.; CAJACOB, C.A. Investigations into glyphosate resistant horseweed (Conyza canadensis): retention, uptake, translocation and metabolism. Weed Science, v.52, p.498-505, 2004.

FERREIRA, E.A.; GALON, L.; ASPIAZÚ, I.; SILVA, A.A.; CONCENÇO, G.; SILVA, A.F.; OLIVEIRA, J.A.; VARGAS, L. Glyphosate translocation in Hairy Fleabane (Conyzabonariensis) biotypes. Planta Daninha, v.26, p.637-643, 2008.

HANF, M. The arable weeds of Europe with their seedlings and seeds. Ludwigshafen: BASF, 1983. 494p.

HESS, M.; BARRALIS, G.; BLEIHOLDER, H.; BUHRS, L.; EGGERS, T.H.; HACK, H.; STAUSS, R. Use of the extended $\mathrm{BBCH}$ scale - general for descriptions of the growth stages of mono-and dicotyledonous weed species. Weed Research, v.37, p.433-441, 1997.

HORAK, M.J.; LOUGHIN, T.M. Growth analysis of four Amaranthus species. Weed Science, v.48, p.347-355, 2000.

HUNT, R. Basic growth analysis: plant growth analysis for beginners. London: Unwin Hyman, 1990. 112p.

ISMAIL, B.S.; CHUAH, T.S.; SALMIJAH, S.; TENG, Y.T.; SHUMACHER, R.W. Germination and seedling emergence of glyphosate-resistant and susceptible biotypes of goosegrass (Eleusine indica). Weed Biology and Management, v.2, p.177$185,2002$.

JAKELAITIS, A.; SILVA, A.A.; FERREIRA, L. R.; SILVA, A.F.; PEREIRA, J.L.; VIANA, R.G. Efeitos de herbicidas no consórcio de milho com Brachiaria brizantha. Planta Daninha, v.23, p.69$78,2005$.

KISSMANN, K.G.; GROTH, D. Plantas infestantes e nocivas. 2.ed. São Paulo: BASF, 1999. v.2. 978 p.

KOGER, C.H.; REDDY, K.N. Role of absorption and translocation in the mechanism of glifosato resistance in horseweed (Conyza canadensis). Weed Science, v.53, p.84-89, 2005.

LÓPEZ-OVEJERO, R.F.; CARVALHO, S.J.P.; CHRISTOFFOLETI, P.J. Recomendações gerais para manejo integrado de plantas daninhas resistentes a herbicidas. In: CHRISTOFFOLETI, P.J. (Coord.). Aspectos de resistência de plantas daninhas a herbicidas. Piracicaba: HRAC-BR, 2008. p.109-120.

LÓPEZ-OVEJERO, R.F.; NOVO, M.C.S.S.; CARVALHO, S.J.P.; NICOLAI, M.; CHRISTOFFOLETI, P.J. Crescimento e competitividade de biótipos de capim-colchão resistente e 
suscetível aos herbicidas inibidores da enzima acetil coenzima A carboxilase. Pesquisa Agropecuária Brasileira, v.42, p.1-8, 2007.

MONQUERO, P.A.; CHRISTOFFOLETI, P.J.; OSUNA, M.D.; DE PRADO, R.A. Absorção, translocação e metabolismo do glyphosate por plantas tolerantes e suscetíveis a este herbicida. Planta Daninha, v.22, p.445-451, 2004.

MOREIRA, M.S.; NICOLAI, M.; CARVALHO, S.J.P.; CHRISTOFFOLETI, P.J. Resistência de Conyza canadensis e $C$. bonariensis ao herbicida glyphosate. Planta Daninha, v.25, p. 157-164, 2007.

PEDERSEN, B.P.; NEVE, P.; ANDREASEN, C.; POWLES, S.B. Ecological fitness of a glifosato resistant Lolium rigidum population: growth and seed production along a competition gradient. Basic Applied Ecology, v.8, p.258-268, 2007.

POWLES, S.B.; PRESTON, C. Evolved glyphosate resistance in plants: biochemical and genetic basis of resistance. Weed Technology, v.20, p.282-289, 2006.

RADOSEVICH, S.R.; HOLT, J.S.; GHERSA, C. Weed ecology: implications for management. 2.ed. New York: John Willey, 1997. 589p.

SATHASIVAN, L.G.; HAUGHN, G.W.; MURAI, N. Nucleotide sequence of a mutant acetolactate synthase gene from an imidazolinone-resistant Arabidopsis thaliana var. Columbia. Nucleic Acids Research, v.18, p. 2188, 1990.

STREIBIG, J.C. Herbicide bioassay. Weed Research, v.28, p.479-484, 1988.

THEBAUD, C.; ABBOTT, R.J. Characterization of invasive Conyza species (Asteraceae) in Europe: quantitative trait and isoenzyme analysis. American Journal of Botany, v.82, p. 360368, 1995.

THEBAUD, C.; FINZI, A.C.; AFFRE, L.; DEBUSSCHE, M.; ESCARRE, J. Assessing why two introduced Conyza differ in their ability to invade Mediterranean old fields. Ecology, v. 77, p. 791-804, 1996.

VARGAS, L.; ROMAN, E.S.; RIZZARDI, M.A.; SILVA, V.C. Alteração das características biológicas de biótipos de Azevém (Lolium multiflorum) ocasionada pela resistência ao herbicida glyphosate. Planta Daninha, v.23, p.153-160, 2005.

VIDAL, R.A.; TREZZI, M.M.Análise de crescimento de biótipos de leitera (Euphorbia heteroplylla) resistentes e suscetível aos herbicidas inibidores da ALS. Planta Daninha, v. 18, p.427433, 2000.

WARWICK, S.; BLACK, I.L.D. Relative fitness of herbicideresistant and susceptible biotypes of weeds. Phytoprotection, v.75, p.37-49, 1994. 